\title{
Estudo longitudinal da infecção por enteropatógenos em bezerros neonatos, com diarreia, sob diferentes estratégias de aleitamento ${ }^{1}$
}

\author{
Júlia G. Carvalho²*, Antônio U. Carvalho², Marcos B. Heinemann³ ${ }^{3}$ Sandra G. Coelho", \\ Paulo R.O. Paes ${ }^{2}$, Gustavo H.F.A. Moreira ${ }^{2}$, Letícia C. Vespasiano ${ }^{2}$ e Elias J. Facury Filho ${ }^{2}$
}

\begin{abstract}
Carvalho J.G., Carvalho A.U., Heinemann M.B., Coelho S.G., Paes P.R.O., Moreira G.H.F.A., Vespasiano L.C. \& Facury Filho E.J. 2014. [Longitudinal study of infection by enteropathogens in newborn calves with diarrhea under different feeding strategies.] Estudo longitudinal da infecção por enteropatógenos em bezerros neonatos, com diarreia, sob diferentes estratégias de aleitamento. Pesquisa Veterinária Brasileira 34(6):529-536. Departamento de Clínica e Cirurgia Veterinárias, Escola de Veterinária, Universidade Federal de Minas Gerais, Av. Antônio Carlos 6627, Belo Horizonte, MG, 30161-970, Brazil. E-mail: juliavetufmg@yahoo.com.br

Seventeen Holstein newborn calves were used with the objective of evaluating the influence of milk replacer volume in the pattern of pathogens causing neonatal diarrhea. The animals were divided into two groups, 8 calves in group 1 and 9 calves in group 2. The calves were fed twice daily in the total of 4 liters of milk replacer to group 1 and 6 liters to group 2. From the $1^{\text {st }}$ day of arrival of the calves feces were evaluated daily after the morning feeding for the classification of diarrheal feces or without diarrhea. The first day of diarrhea until the seventh day, feces were collected on alternate days $\left(1^{\text {st }}, 3^{\text {rd }}, 5^{\text {th }}\right.$ and $7^{\text {th }}$ day) directly from the rectum to evaluate enteropathogens. Were collected blood samples from calves with five days of age for determination of total protein. The average total protein was 6.33 and $6.21 \mathrm{~g} / \mathrm{dL}$ in groups 1 and 2 , respectively. The group 2 tended $(\mathrm{p}<0.1)$ higher consumption of milk replacer during the study period. The volume of milk replacer did not influenced the incidence of diarrhea and the frequency of positive samples for each etiologic agent between the two groups ( $p>0.05)$. Also, there was no difference ( $p>0.05)$ on the pattern of the frequency of positive samples for evaluated pathogens. The frequency of pathogens in the samples was 100 and $75 \%$ for Cryptosporidium, 28.5 and $43.7 \%$ for Salmonella spp., 28.5 and $15.6 \%$ for E. coli pathotypes, 3.5 and 6.2\% for Rotavirus and 10.7 and 9.4\% for Giardia in groups 1 and 2, respectively. Serotypes of Salmonella infantis and muenster were found. The isolated pathotypes of $E$. coli isolates were classified as Escherichia coli enteropathogenic, enterotoxigenic and Shiga-toxin-producing 1 and 2. Associations between Cryptosporidium spp. and E. coli pathotypes, and between Cryptosporidium spp. and Salmonella spp. were found in 30\% of the samples in group 1 and in $45.5 \%$ in group 2, respectively. Our results showed that the different volumes of milk replacer did not influence the incidence and etiology of neonatal diahrrea. Longitudinal evaluation of enteropathogens during patency demonstrated that the association between the etiologic agents starts from the first day of disease. This result highlighted the great importance of the infection by Cryptosporidium spp. which was present in every moments and animals evaluated.
\end{abstract}

INDEX TERMS: Diarrhea, calves, enteropathogens, milkreplacer, feeding strategies.

\footnotetext{
${ }^{1}$ Recebido em7 de março de 2014.

Aceito para publicaçlão em 3 de junho de 2014.

${ }^{2}$ Departamento de Clínica e Cirurgia Veterinárias, Escola de Veterinária, Universidade Federal de Minas Gerais, Avenida Antônio Carlos 6627, Pampulha, Belo Horizonte, MG 30161-970, Brasil. *Autor para correspondência: juliavetufmg@yahoo.com.br
}

\footnotetext{
2 Departamento Medicina Veterinária Preventiva, Escola de Veterinária, Universidade Federal de Minas Gerais, Avenida Antônio Carlos 6627, Belo Horizonte, MG 30161-970.

${ }^{2}$ Departamento Zootecnia, Escola de Veterinária, Universidade Federal de Minas Gerais, Avenida Antônio Carlos 6627, Pampulha, Belo Horizonte, MG 30161-970.
} 
RESUMO.- Foram utilizados 17 bezerros, recém nascidos, da raça Holandesa, com o objetivo de avaliar a influência do volume de sucedâneo nos principais patógenos causadores de diarreia neonatal. Os animais foram distribuídos em dois grupos, 8 bezerros do grupo 1 e 9 bezerros do grupo 2. Os animais foram alimentados duas vezes ao dia totalizando 4 litros de sucedâneo diários para o grupo 1 e 6 litros para o grupo 2 . A partir do $1^{\circ}$ dia de chegada dos bezerros foram avaliadas as fezes diariamente após o aleitamento da manhã para a classificação das fezes em diarreicas ou não diarreicas. Do primeiro dia de diarreia até o sétimo dia, as fezes foram coletadas em dias alternados $\left(1^{\circ}, 3^{\circ}, 5^{\circ}\right.$ e $7^{\circ}$ dia $)$ diretamente da ampola retal para avaliação dos enteropatógenos. Foram coletadas amostras de sangue dos bezerros com cinco dias de idade para dosagem da proteína total. A média da proteína total foi 6,33 e $6,21 \mathrm{~g} / \mathrm{dL}$ nos grupos 1 e 2 respectivamente. 0 grupo 2 apresentou tendência $(p<0,1)$ de maior consumo de sucedâneo no período avaliado. A quantidade de sucedâneo oferecida aos animais não influenciou a incidência de diarreia e sua etiologia, ou seja, não foi observada diferença $(p>0,05)$ na frequência das amostras positivas para cada agente entre os grupos. A frequência dos enteropatógenos nas amostras foi de 100 e $75 \%$ para Cryptosporidium spp.; 28,5 e 43,7\% para Salmonella spp.; 28,5 e 15,6\% para patotipos de E. coli; 3,5 e 6,2\% para Rotavírus e 10,7 e 9,4\% para Giardia sp. nos grupos 1 e 2 respectivamente. Foram encontrados os sorotipos de Salmonella infantis e muenster. Os patotipos de $E$. coli isolados foram classificados como E. coli enterohemorrágica, enteropatogênica, enterotoxigênica e produtoras de toxinas Shiga 1 e 2. Foi observada associação entre o Cryptosporidium spp. e os patotipos de E. coli em 30\% das amostras do grupo 1 e Cryptosporidium spp. e Salmonella spp. em $45,5 \%$ no grupo 2. Os resultados do presente trabalho demonstraram que o fornecimento de diferentes volumes de sucedâneo não apresentou influência sobre a incidência e etiologia da diarreia neonatal. A avaliação longitudinal dos enteropatógenos durante o período de patência da diarreia demonstrou que a associação entre eles ocorre a partir do primeiro dia da doença e destacou a importância da infecção pelo Cryptosporidium spp. agente encontrado em todos os momentos e animais.

TERMOS DE INDEXAÇÃO: Diarreia, bezerros, enteropatógenos, sucedâneo, aleitamento.

\section{INTRODUÇÃO}

A diarreia em bezerros é uma doença multifatorial e, apesar de décadas de pesquisas sobre o assunto, ainda é a causa mais frequente de morte em neonatos (Lorenz 2006). A diarreia contribui de $50 \%$ a $75 \%$ das mortes de bezerros com até três semanas de idade, com morbidade de $90 \%$ a $100 \%$ neste período, resultando assim em consideráveis perdas econômicas para o sistema de produção (Langoni et al. 2004, Freitas 2009).

A síndrome diarreica neonatal ocorre como resultado da interação entre fatores relacionados ao bezerro, ao manejo e ao ambiente, incluindo colostragem, condições sanitárias, instalações, estratégia de agrupamento, nutrição, estresse e exposição a um ou mais agentes infecciosos (Hall et al. 2004). Dentre os agentes infecciosos envolvidos na diarreia, a literatura ressalta como mais frequentes a $E s$ cherichia coli, Salmonella spp., Coronavírus, Rotavírus, Cryptosporidium spp., Giardia sp. e Eimeria spp., sendo comum as infecções mistas por esses agentes (Tzipori et al. 1980).

De acordo com Drackley (2008) existem evidências de que bezerros com dietas para crescimento acelerado são mais resistentes à diarreia bem como a doenças respiratórias. Além disso, foi observado que aqueles animais quando apresentam diarreia, tendem a recuperar-se mais rapidamente com menor impacto sobre a taxa de crescimento durante a doença.

$\mathrm{O}$ fornecimento de maior quantidade de leite ou sucedâneo tem benefícios também sobre a imunidade dos bezerros. Deficiências nutricionais estão relacionadas à depressão simultânea de vários mecanismos de defesa do sistema imune, como diminuição da concentração de IgA e da liberação de citocinas como IL-1, IL-6 e TNF- $\alpha$, além do comprometimento dos mecanismos antioxidantes. Com a imaturidade do sistema imunológico dos bezerros neonatos e maior susceptibilidade a doenças, a nutrição adequada em bezerros pode ter efeitos positivos sobre a resposta imune e, consequentemente, melhorar a resposta às doenças neste período de vida (Woodward 1998, Nonnecke et al. 2003, Silper et al. 2014).

Grande parte dos dados existentes na literatura sobre enteropatógenos em bezerros neonatos abordam agentes específicos, em estudos de prevalência deixando uma lacuna sobre o comportamento longitudinal e a interação desses agentes na diarreia neonatal. Dessa forma, o objetivo deste trabalho foi avaliar o comportamento longitudinal dos principais agentes envolvidos na diarreia neonatal de bezerros e a influência da estratégia de aleitamento na etiologia da diarreia.

\section{MATERIAL E MÉTODOS}

Foram utilizados 17 bezerros machos, recém nascidos, da raça Holandesa, oriundos de uma mesma propriedade leiteira, localizada no município de Inhaúma, Minas Gerais. Logo após o nascimento, foi realizada a cura do umbigo com solução de iodo e a colostragem com auxílio de mamadeira, sendo fornecido o volume de dois litros de colostro nas primeiras duas horas de vida. Em seguida os animais foram levados para uma baia coletiva com cama de feno.

Os animais foram transferidos nos primeiros dias de vida (1-3 dias) para um piquete da Escola de Veterinária da Universidade Federal de Minas Gerais e alojados em um bezerreiro tipo Argentino, caracterizado por áreas individuais com 15 metros quadrados por animal, contidos através de uma corrente de 1,5m, ligada a um fio de arame de 5 metros de comprimento. Em uma das extremidades do arame havia suporte para dois baldes e na outra extremidade, uma área de sombra com $8,5 \mathrm{~m}^{2} /$ animal proveniente de uma tela com $80 \%$ de bloqueio solar. A temperatura mínima variou entre 15 e $29^{\circ} \mathrm{C}$ e a máxima entre 23 e $41^{\circ} \mathrm{C}$. A pluviosidade foi de $600 \mathrm{~mm}$ em três meses.

Os bezerros foram inicialmente aleitados com quatro litros de sucedâneo (Lacthor - Tortuga, Companhia Zootécnica Agrária, São Paulo, Brasil) por dia até o terceiro dia de vida para adaptação e posteriormente iniciou-se o tratamento pré-definido. Receberam também água e concentrado à vontade. Os bezerros foram distribuídos em dois grupos, 8 bezerros do grupo 1 e 9 bezerros do grupo 2. Para o grupo 1 foram oferecidos 4 litros de sucedâneo 
ao dia, e para o grupo 2, 6 litros, sendo esta quantidade dividida igualmente em duas refeições diárias. Os bezerros com diarreia foram tratados com fluidoterapia oral segundo Freitas (2013).

Foram coletadas amostras de sangue $(5 \mathrm{~mL})$ dos bezerros com cinco dias de vida para dosagem da concentração de proteína total, por punção da jugular, utilizando tubos a vácuo sem anticoagulante. As amostras de sangue foram imediatamente centrifugadas após a coleta a $3500 \mathrm{rpm}$ por dez minutos, aliquotadas em microtubos de congelamento de $0,5 \mathrm{~mL}$ e conservadas congeladas a $-20^{\circ} \mathrm{C}$. A proteína total foi dosada em aparelho semiautomático, utilizando kit comercial (Sinermed ${ }^{\circledR}$ ).

As fezes foram avaliadas diariamente a partir do $1^{\circ}$ dia de chegada dos bezerros, após o aleitamento da manhã, através da estimulação retal e classificadas em diarreicas ou não diarreicas. Do primeiro ao sétimo dia de diarreia, as fezes foram coletadas em dias alternados $\left(1^{\circ}\right.$, $3^{\circ}$, $5^{\circ}$ e e $7^{\circ} \stackrel{0}{)}$, em sacos plásticos, diretamente da ampola retal para avaliação dos enteropatógenos. Após a coleta, as amostras foram resfriadas a $4^{\circ} \mathrm{C}$ e na mesma semana processadas para avaliação dos enteropatógenos.

Foi diluído $1 \mathrm{~g}$ de fezes em tampão de estabilização de rotavírus (TERV) em proporção 1:4 e congelada para pesquisa dos agentes virais. Parte desta suspensão fecal $(3 \mathrm{~mL})$ foi aliquotada em microtubos de congelamento de $1,5 \mathrm{~mL}$ e armazenada a $-20^{\circ} \mathrm{C}$ para posterior exame virológico. 0 diagnóstico de Rotavírus bovino foi realizado por meio da técnica padrão de eletroforese em gel de poliacrilamida (SDS-PAGE) segundo Herring et al. (1982).

Para a pesquisa das enterobactérias, um $\mathrm{mL}$ daquela suspensão fecal em TERV foi transferida para o meio não seletivo de pré-enriquecimento (água peptonada) e incubado a $37^{\circ} \mathrm{C}$ por $18-24$ h. Após este período, com auxílio de alça flambada, as amostras foram repicadas em ágar MacConkey, sendo as placas incubadas na estufa a $37^{\circ} \mathrm{C}$, para isolamento de Escherichia coli. Para isolamento de Salmonella spp., uma alíquota (um $\mathrm{mL}$ ) do meio de pré-enriquecimento não seletivo foi transferida para o meio seletivo Tetrationato de Sódio, sendo novamente incubado à $37^{\circ} \mathrm{C}$ em aerobiose por mais $24 \mathrm{~h}$. Em seguida foi semeado em placas de ágar XLT-4 e ágar Hektoen, específicos para Salmonella spp. (Waltman 2000).

De cada placa estriada foram selecionadas até três colônias que apresentavam aspecto morfológico sugestivo de E. coli ou Salmonella. Para identificação de Salmonella foi realizado a técnica de PCR segundo Silva et al. (2009). As colônias classificadas como Salmonella spp. foram enviadas ao Laboratório de Referência em Salmonella no IOC/Fiocruz, Rio de Janeiro/RJ, para sorotipagem pela técnica de aglutinação rápida baseada nas fórmulas antigênicas para Salmonella (Popoff \& Minor 2001).

Os fatores de virulência de $E$. coli foram identificados pela técnica de PCR multiplex utilizando pares de primers para detecção dos genes codificadores para K99, F41, intimina(eae), toxina Shiga 1 e 2 (Stx1 e Stx2, respectivamente) e toxina termo-estável (STa) (Franck et al. 1998).

A contagem do número de oocistos de Eimeria spp. por grama de fezes (OOPG) foi realizada na câmara de McMaster, pelo método de Gordon e Whitelock Modificado (Ueno \& Gonçalves 1998) e a pesquisa qualitativa dos oocitos de Cryptosporidium spp. através do método de centrífugo-sedimentação em água-éter e coloração modificada de Ziehl-Neelsen (Garcia \& Bruckner 1997). A pesquisa qualitativa de cistos de Giardia sp. foi feita através da concentração por centrífugo-flutuação em solução saturada de sacarose (Ogassawara et al. 1989).

A avaliação do comportamento dos enteropatógenos durante os momentos da diarreia $(1,3,5$ e 7$)$ foi realizada de forma descritiva. Para o tratamento estatístico foi realizado teste de hipótese utilizando o teste F para os contrastes entre os volumes de sucedâneo (4x6 litros). Para as variáveis qualitativas (frequência dos enteropatógenos entre os grupos 1 e 2) foi utilizado o teste exato de Fisher. A proteína total foi avaliada entre os grupos pelo teste de Tukey. Comparações com $\mathrm{p} \leq 0,05$ foram consideradas significativas, enquanto que comparações com $p \leq 0,10$ foram apresentadas como tendências. As análises estatísticas foram realizadas utilizando os procedimentos do software SAEG (SAEG, 2000).

\section{RESULTADOS}

Durante o período experimental todos os bezerros apresentaram diarreia, que perdurou durante os sete dias de coleta de material. A média de idade dos bezerros no início da diarreia foi de 5,9 dias no grupo 1 e 5,1 no grupo 2 .

Ocorreram quatro mortes de bezerros durante o período das coletas, sendo dois do grupo 1 e dois do grupo 2 . Três dessas mortes ocorreram aos três dias de idade e uma aos seis dias (bezerro do grupo 2).

As concentrações de proteína total (PT) mensuradas nos bezerros aos cinco dias de vida demonstraram valores acima de 5,5g/dl em todos os animais e valores médios de 6,33 e de 6,21g/dl para os grupos 1 e 2 respectivamente $(\mathrm{p}>0,05)$. Nos primeiros dias de vida, o consumo de sucedâneo de leite pelos dois grupos foi semelhante, por volta de quatro litros diários, apesar do oferecimento de seis litros para o grupo 2. Durante o período de diarreia, o grupo 1 apresentou uma tendência de diminuição do consumo de leite, que foi em média 3,24 litros ( $p<0,1$ ) (Quadro 1).

Para a comparação da frequência dos enteropatógenos entre grupos com diferentes estratégias de aleitamento, considerou-se o número total de amostras de fezes positivas para cada agente. Desta forma, foram examinadas 28 e 32 amostras, respectivamente nos grupos 1 e 2 , oriundas de quatro momentos de coleta. Não foi observada diferença estatística $(p>0,05)$ entre as frequências das amostras positivas para cada agente entre os grupos 1 e 2 ( $4 \mathrm{~L}$ x 6L), conforme observado no Quadro 2. Isso significa que o volume de sucedâneo não interferiu na frequência dos agentes durante o período de diarreia.

Cryptosporidium spp. foram os agentes de maior frequência, foi diagnosticado nas amostras de fezes de todos os animais dos dois grupos, em todos os momentos da diarreia e estava presente em 73\% das amostras avaliadas (Quadro2; Fig.1). No início dos quadros de diarreia, este protozoário foi o agente mais frequente e em torno do quinto e sétimo dia, estava presente em todos os animais. No grupo 1, Cryptosporidium spp. foi encontrado em 100\% dos bezerros e em 75\% das amostras. Foram positivos para Cryptosporidium spp. 37,5\%, 71,43\%, 100\% e $100 \%$

\begin{tabular}{|c|c|c|c|c|}
\hline & Grupo 1 & Grupo 2 & $\mathrm{CV}$ & $\mathrm{P}$ \\
\hline Antes da diarreia & 3,99 & 4,01 & & \\
\hline Durante a diarreia (1-7 dias) & 3,24 & 4,09 & & \\
\hline Média & $3,62 \mathrm{~A}$ & $4,09 B$ & 18,22 & $0,057 * * *$ \\
\hline Desvio padrão & 0,76 & 0,62 & & \\
\hline
\end{tabular}

Médias seguidas por letras maiúsculas distintas na linha diferem entre si pelo teste $\mathrm{F}(\mathrm{p}<0,05)$ ns. $\mathrm{CV}=$ coeficiente de variação $(\%) .{ }^{*} \mathrm{p}<0,01 .{ }^{* *}$ $\mathrm{p}<0,05, * * *$ tendência $\mathrm{p}<0,1$. 
Quadro 2. Frequência (\%) de animais e amostras positivas por enteropatógeno no grupo 1 (oferecido 4 litros de sucedâneo) e grupo 2 (oferecido 6 litros de sucedâneo)

\begin{tabular}{|c|c|c|c|c|}
\hline \multirow[t]{2}{*}{ Agentes } & \multicolumn{2}{|c|}{ Grupo 1} & \multicolumn{2}{|c|}{ Grupo 2} \\
\hline & $\begin{array}{c}\text { Animais posi- } \\
\text { tivos } \% \mathrm{n}=8\end{array}$ & $\begin{array}{l}\text { Amostras posi- } \\
\text { tivas } \% \mathrm{n}=28\end{array}$ & $\begin{array}{c}\text { Animais posi- } \\
\text { tivos } \% \mathrm{n}=9\end{array}$ & $\begin{array}{c}\text { Amostras posi- } \\
\text { tivas } \% \mathrm{n}=32\end{array}$ \\
\hline Cryptosporidium & 100,0 & 75,0 & 100,0 & 71,9 \\
\hline Rotavirus & 12,5 & 3,5 & 22,2 & 6,2 \\
\hline Eimeria & 0,0 & - & 0,0 & - \\
\hline Giardia & 37,5 & 10,7 & 33,3 & 9,4 \\
\hline Escherichia Coli & 75,0 & 28,5 & 22,5 & 15,6 \\
\hline Salmonella spp. & 50,0 & 28,5 & 66,6 & 43,7 \\
\hline
\end{tabular}

Médias seguidas por letras diferentes maiúsculas nas linhas diferem entre si pelo teste Exato de Fisher $(p<0,05)$.

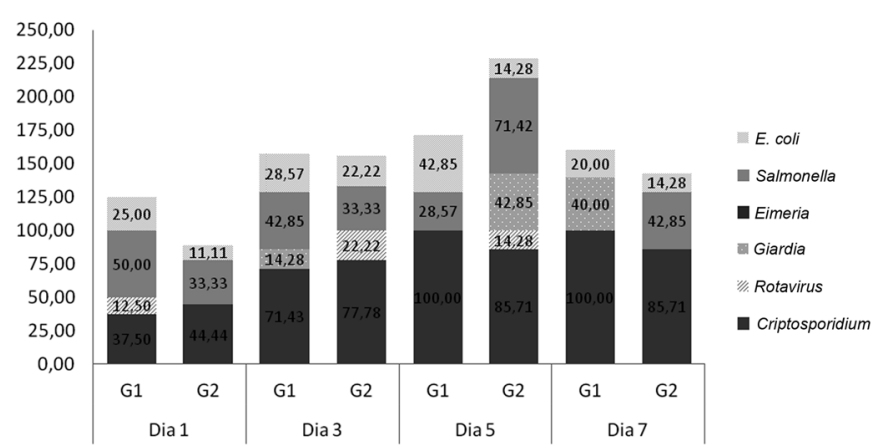

Fig.1. Frequência (\%) de amostras positivas no período da diarreia $(1,3,5$ e 7$)$ para cada agente etiológico no grupo 1 (oferecido 4 litros de sucedâneo) e 2 (oferecido 6 litros de sucedâneo).

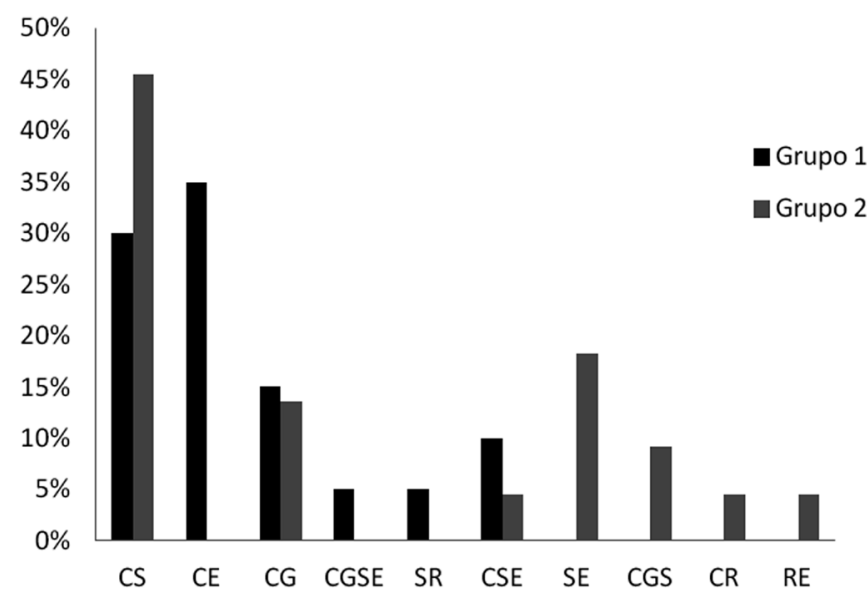

Fig.2. Frequência das associações das infecções entéricas no grupo 1 (oferecido 4 litros de sucedâneo) e grupo 2 (oferecido 6 litros de sucedâneo $).(\mathrm{C}=$ Cryptosporidium, $\mathrm{S}=$ Salmonella, $\mathrm{E}=\mathrm{E}$. coli, $\mathrm{G}=$ Giardia, $\mathrm{R}=$ Rotavirus )

dos bezerros, nos dia 1, 3, 5 e 7 de diarreia respectivamente (Fig.1). No grupo 2, a frequência de amostras positivas foi de $71,9 \%$, e durante os dias de diarreia foi de $44,44 \%$, $77,78 \%, 85,71 \%$ e $85,71 \%$ nos dias $1,3,5$ e 7 , respectivamente (Fig.1). A associação de Cryptosporidium spp. com outros agentes foi observada em $61,9 \%$ das amostras positivas para Cryptosporidium spp., sendo que $30 \%$ dessas estavam associadas a patotipos de E. coli no grupo 1 e 45,5\% com Salmonella spp. no grupo 2 (Fig.2).
Patotipos de E. coli (amostras com gene de virulência) foram identificados em $75 \%$ dos animais e $28,5 \%$ das amostras de fezes do grupo 1 e em 22,5\% dos animais e 15,6\% das amostras do grupo 2 (Quadro 2). A E. coli (Fig.1) foi encontrada em todos os dias avaliados nos dois grupos apresentando maior frequência no $5^{\circ}$ dia no grupo $1(42,85 \%)$ e no $3^{\circ}$ dia no grupo $2(22,22 \%)$. No grupo 1 , a associação entre patotipos de E. coli e Cryptosporidium spp. foi de 35\% enquanto, que no grupo 2, observou-se $18,2 \%$ de associação com Salmonella spp. (18,2\%) (Fig.2). Das amostras positivas para E. coli (patogênica) do grupo 1, 3 amostras foram classificadas como EHEC (E. coli enterohemorrágica), 3 como EPEC (E. coli enteropatogênica), 1 como ETEC (E. coli enterotoxigênica) e 1 STEC (E. coli produtora de toxinas Shiga $1 \mathrm{e} / \mathrm{ou} 2$ ). Um bezerro do grupo 1 apresentou o patotipo ETEC de E. coli aos três dias de idade, sendo o mais jovem a apresentar diarreia nesse grupo. 0 grupo 2 apresentou 5 amostras positivas para patotipos de E. coli, sendo 2 classificadas como EHEC, 1 como EPEC, 1 como ETEC e 1 como ETEC e STEC sendo esse o bezerro que apresentou o quadro mais precoce de diarreia no segundo grupo, 2 dias de idade.

A Salmonella spp. foi isolada em alta frequência neste estudo, sendo diagnosticada em 50\% dos animais do G1 e 66\% do G2 (Quadro2). Este agente foi diagnosticado em $22,5 \%$ e $43,7 \%$ das amostras fecais, nos grupos 1 e 2, respectivamente (Quadro2). No grupo 1, Salmonella spp. estiveram presentes nos dias $1(50 \%), 3(42,85 \%)$ e $5(28,57)$ e no grupo 2, nos dias $1(33,33 \%), 3(33,33 \%), 5(71,42 \%)$ e 7 (42,85\%) (Fig.1). As amostras positivas de Salmonella foram classificadas quanto ao sorotipo. Das $23(100 \%)$ amostras positivas dos dois grupos, 10 foram classificadas como Salmonella Muenster (43,5\%), 4 como Salmonella Infantis $(17,4 \%)$ e 9 tiveram infecção mista por Salmonella Muenster e Salmonella Infantis $(39,1 \%)$.

o Rotavírus foi identificado em 12,5\% dos animais do grupo 1 e em $22,23 \%$ do grupo 2 (Quadro 2). Sua participação nos casos de diarreia foi discreta e intermitente. 0 grupo 1 apresentou o vírus apenas no primeiro dia de diarreia $(12,5 \%)$ e o grupo 2 no terceiro dia de diarreia $(22,23 \%)$ (Fig.1). No grupo 1, o Rotavírus foi encontrado associado a Salmonella spp. (Fig.1) apenas em 1 animal e no grupo 2 associado a Cryptosporidium spp., também em um indivíduo.

A infecção por Giardia sp. foi diagnosticada em 37,5\% dos animais no grupo 1 e 33,3\% no grupo 2 (Quadro 2). A frequência nas amostras fecais foi 10,7 e 9,4\% nos grupos 1 e 2, respectivamente, no período da diarreia (Quadro 2). A frequência do agente no grupo 1 foi $0 \%, 14,28 \%, 0 \%$ e $40 \%$ nos dias 1, 3, 5 e 7 de diarreia respectivamente (Fig.1). No grupo 2 foram encontrados cistos de Giardia sp. apenas no dia 5 de diarreia com uma frequência de $42,85 \%$ neste dia. Em 15\% das associações (Fig.2) foi observada associação entre Giardia sp. e Cryptosporidium spp. no grupo 1 e um bezerro apresentou simultaneamente Cryptosporidium spp., Giardia sp., Salmonella spp. e patotipos de E. coli. No grupo 2, ocorreu associação de Giardia sp. com Cryptosporidium spp. em $13,6 \%$ das amostras e 9,2\% da associação Cryptosporidium spp., Giardia sp. e Salmonella spp.

A eimeriose não foi identificada em nenhum dos animais do grupo 1 e do grupo2 (Quadro 1). 


\section{DISCUSSÃO}

Os bezerros apresentaram diarreia precocemente, ainda na primeira semana de vida independente da estratégia de aleitamento. Coura (2011), trabalhando em uma fazenda leiteira em sistema semi-intensivo em Minas Gerais, também observou incidência de diarreia de $100 \%$ em bezerros de 0 a 60 dias, sendo observada maior ocorrência na segunda semana de vida. Trotz-Williams et al. (2007) e Bartels et al. (2010) também encontraram maior prevalência de diarreia na segunda semana de vida dos bezerros. 0 inicio precoce da diarreia pode ter sido influenciado pelo maior grau de desafio dos bezerros em relação ao ambiente, uma vez que a síndrome diarreica neonatal é um complexo que ocorre como resultado da interação entre o animal, fatores de manejo e fatores ambientais, incluindo manejo de colostro, manejo sanitário, instalações, estratégia de agrupamento, ventilação, estresse, nutrição e exposição a um ou mais agentes infecciosos (Hall et al. 2004). Durante o experimento quatro bezerros morreram em decorrência da diarreia e da desidratação. As amostras de fezes desses animais foram utilizadas, uma vez que esses foram avaliados do momento da chegada até o momento do óbito, durante o curso da diarreia. A maioria das causas de mortalidade em bezerros, do nascimento ao desmame são em decorrência das diarreias e dos problemas respiratórios, causando grande impacto econômico (Davis \& Drackley 1998, McGuirk 2008).

Os valores médios de proteína sérica total dos dois grupos demonstraram que ocorreu adequada transferência de imunidade passiva, uma vez que Godden (2008) afirma que $80 \%$ dos bezerros de um rebanho devem apresentar proteína total acima de 5,5g/dL para se considerar boa a colostragem. Todos os bezerros apresentaram valores de proteína total acima deste limite, comprovando a boa colostragem. Apesar disso, a incidência de diarreia nos bezerros foi de $100 \%$, demonstrando que esta enfermidade atinge também animais com boa transferência de imunidade passiva. 0 banco de colostro utilizado neste trabalho foi formado por colostros oriundos de várias propriedades, o que pode ter contribuído para uma variação na sua qualidade em relação à especificidade dos anticorpos.

A tendência de maior consumo de sucedâneo do grupo 2 em relação ao grupo 1 ocorreu devido ao oferecimento de maior volume, o que pode ter estimulado o bezerro a consumir mais sucedâneo. Segundo Silper et al. (2014), o consumo médio no primeiro mês de vida de bezerros foi inferior no grupo que recebeu 4 litros de leite/dia em relação ao grupo em que foi oferecido 6 litros/dia. 0 volume tradicionalmente utilizado, equivalente a $10 \%$ do peso do bezerro, fornece nutrientes apenas para mantença e ganho de peso de no máximo $300 \mathrm{~g} /$ dia em condições termoneutras (Drackley 2008), sendo, portanto, insuficientes para ganhos esperados de 600-700g/dia nas criações intensivas de bezerros em condições climáticas, na maioria dos casos, fora da zona de conforto. É interessante observar que mesmo durante a diarreia, os bezerros aos quais era oferecido maior volume de sucedâneo, consumiram maior quantidade, o que pode influenciar positivamente na correção do equilíbrio ácido base e de eletrólitos nestes animais.
A quantidade de sucedâneo oferecida aos animais não influenciou a incidência de diarreia e sua etiologia. Não foi observada diferença $(p>0,05)$ na frequência das amostras positivas para cada agente entre os grupos (Quadro 2). Os bezerros ficaram em uma área reduzida, em um ambiente com umidade elevada, muita matéria orgânica durante um período de alta pluviosidade e temperatura elevada. Foi observada também a presença de grande número de pássaros atraídos pela ração nos baldes, sendo esses possíveis vetores mecânicos, favorecendo a dispersão dos patógenos. Isso contribuiu para maior dispersão e exposição dos animais aos agentes, uma vez que a via principal de infecção dos agentes estudados é oral-fecal tendo o ambiente influencia na ocorrência dos enteropatógenos (Radostits et al. 2007). Tais fatores podem ter contribuído para a manutenção no ambiente de altas cargas infecciosas de agentes bacterianos, como Salmonella e E. coli e do Cryptosporidium spp., os quais foram identificados como principais agentes no primeiro dia de diarreia neste trabalho.

Cryptosporidium spp. apresentam período pré-patente de 3 a 6 dias, compatível, portanto, com o início da diarreia ainda na primeira semana de vida. Sua maior frequência em fezes de bezerros é observada em torno da segunda e terceira semanas de vida (Fayer et al. 1998). Ortolani e Soares (2003) observaram que a criptosporidiose está amplamente distribuída no Brasil, com maior frequência em bezerros de 1 a 3 semanas e que existe correlação entre o diagnóstico do agente e a diarreia. Em Minas Gerais, Ferreira et al. (2009) observou prevalência de 9,2\% do agente em amostras de fezes normais e diarreicas de bezerros entre 5 e 60 dias, utilizando kit de ELISA para o diagnóstico, enquanto Batista et al. (2008) utilizou o mesmo kit e encontrou prevalência de $68 \%$, porém todas as amostras processadas foram oriundas de fezes diarreicas de bezerros com 7 a 14 dias de idade. A alta frequência de associação do Cryptosporidium spp. com agentes bacterianos, principalmente Salmonella spp. e patotipos de E. coli pode ter ocorrido, devido às condições ambientais favoráveis à manutenção de alta carga bacteriana, especialmente o alto índice pluviométrico do período experimental, e a alta densidade de bezerros com faixa etária próxima. Estes resultados contrapõem os encontrados por García et al. (2000) que relataram maior frequência da associação de Cryptosporidium spp. com Rotavírus.

E. coli foi encontrada como agente de diarreia em bezerros muito novos (dois e três dias de idade), com presença dos patotipos ETEC e STEC. A maior frequência de isolamento de patotipos de $E$. coli ocorreu no quinto dia de diarreia no grupo $1(42,85 \%)$ e no terceiro dia no grupo 2 (22,22\%) (Fig.1). Ferreira et al. (2009) observou 90,22\% de bezerras positivas para $E$. coli, no entanto, não encontrou nenhuma amostra com gene de virulência, utilizando o Kit ELISA capaz de identificar apenas E. coli F5, enquanto Andrade et al. (2012) encontrou 96 amostras com genes de virulência do total de 850 amostras positivas para E. coli pela técnica de PCR multiplex. Estes dados indicam que a diversidade da literatura pode estar relacionada não só com as condições de saúde e ambiente, mas também com o método de diagnóstico utilizado. 
A alta frequência de Salmonella spp. encontrada, 50\% dos bezerros do grupo 1 e $66 \%$ do grupo 2 diverge de alguns trabalhos na literatura. Costa et al. (1979) encontraram prevalência de 9\% de Salmonella em fezes diarreicas de bezerros de 0 a 60 dias, resultado semelhante ao de Langoni et al. (2004), porém em bezerros de 0 a 30 dias. Ferreira et al. (2009) e Oliveira Filho et al. (2007) observaram ausência do isolamento da bactéria. Esta divergência de resultados pode ser justificada pela diferença da idade dos bezerros estudados, uma vez que a infecção é mais comum na primeira semana de vida e os sinais clínicos são observados entre duas e seis semanas de idade (Wray \& Davies 2000, Barrow et al. 2010). Outro fator que influencia no isolamento da Salmonella spp. é o intervalo entre a coleta e o processamento do material (Urquhart et al. 1998, Bowman 2006). Desta forma, a alta frequência de isolamento neste trabalho pode estar relacionada às condições ambientais propicias a manutenção ambiental do agente e ao processamento imediato das amostras de fezes, uma vez que o laboratório se localizava no mesmo local da criação de bezerros.

Os sorotipos encontrados tanto no grupo 1 quanto no grupo 2 foram Salmonella Muenster e Salmonella Infantis. Apesar de não ser conhecida como principal causa de salmonelose em bovino de acordo com Radostits et al. (2007), no presente trabalho a Salmonella Muenster foi predominante nos dois grupos. No Canadá, McEwen et al. (1988), encontraram este sorotipo em 2,9\% em amostras de leite cru. Na Finlândia, Salmonella Infantis foi o sorotipo mais encontrado entre os animais e a terceira causa mais comum de salmonelose humana e em animais (Pelkonen et al. 1994). No Brasil, no estado de Pernambuco, Mendonça et al. (1996) encontraram 4,7\% de bezerros positivos para Salmonella, sorotipos Dublin, Muechen e Infantis. Isso demonstra que são necessários mais estudos para esclarecer a epidemiologia da Salmonella Muenster e Infantis no nosso meio, devido a sua presença e por ser uma bactéria que tem demonstrado patogenicidade.

A frequência do Rotavírus foi relativamente baixa nos bezerros com diarreia ao contrario de Buzinaro et al. (2003) em São Paulo que encontraram prevalência desse agente em $63,8 \%$ de amostras de bezerros diarreicos. Em Minas Gerais, Batista (2008) verificou prevalência de $31,8 \%$ de Rotavírus em bezerros diarreicos de uma a duas semanas de idade. Coura (2011), no mesmo estado, observou incidência de $5,76 \%$ em bezerros de 0 a 60 dias, sendo que $69 \%$ das amostras eram de bezerros diarreicos. Foi observado também por Coura (2011) que os bezerros excretaram o vírus por no máximo três dias consecutivos, principalmente na segunda e terceira semanas de vida, além da identificação de uma relação entre o quadro de diarreia e a excreção do Rotavírus. Reynolds et al. (1985) trabalhando com bezerros naturalmente infectados, demonstrou que 83\% dos animais excretaram Rotavírus nas fezes em média por 3,6 dias e cerca de $50 \%$ dos bezerros infectados não apresentaram sinais clínicos durante o período experimental. A patogênese do Rotavírus depende da sua virulência e da idade do bezerro, pois bezerros neonatos possuem lenta reposição de enterócitos, células onde o vírus se replica, fi- cando mais suscetíveis à doença (Dodet et al. 1997). Mayameei et al. (2010) sugerem que a ocorrência de rotavirose é maior na terceira semana, devido aos anticorpos colostrais e a imunidade local presente principalmente na primeira semana de vida e um pouco na segunda, diminuindo a frequência de diarreia por rotavirose neste período.

Não foram encontrados oocistos de Eimeria spp. em nenhuma amostra de fezes de ambos os grupos. Apesar da ração dos bezerros apresentar coccidiostático em sua composição, o consumo de ração durante as duas primeiras semanas é baixo (Silper et al. 2014) não sendo suficiente para fornecer a dose correta do coccidiostático. A Eimeria é um importante agente causador de diarreia em bezerros, os períodos pré-patentes das principais espécies de Eimeria variam de 6-11 dias para E. alabamensis até 15-20 dias para E. bovis e E. zuernii, espécies mais frequentes causando diarreia em bezerros. (Levine 1973, Facury Filho 1992). Portanto, a ausência do diagnóstico desse agente no experimento, parece estar relacionada a idade dos bezerros, inferior ao período pré patente das principais espécies.

A frequência de Giardia sp. nas amostras fecais foi $10,7 \%$ no grupo 1 e 9,4\% no grupo 2 no período de diarreia. Guimarães et al. (2009) encontraram incidência de $100 \%$ em bezerros de 0 a 100 dias em um estudo longitudinal observando que a eliminação, mais precoce, de cistos de Giardia sp. ocorreu no décimo sétimo dia de vida e não estava relacionado com a ocorrência de diarreia. Na Austrália, Becher et al. (2004) observou maior prevalência em bezerros de 4-7 semanas de idade e foi detectado em $89 \%$ dos animais estudados. A frequência da infecção por Giardia no presente trabalho foi baixa, possivelmente devido à idade dos animais, uma vez que, geralmente, a maior prevalência é observada em animais com a idade de 3-5 semanas (Quilez et al. 1996).

\section{CONCLUSÃO}

Os resultados do presente trabalho demonstraram que o fornecimento de diferentes volumes de sucedâneo não apresentou influência sobre a incidência e etiologia da diarreia neonatal. A avaliação longitudinal dos enteropatógenos durante o período de patência da diarreia demonstrou que a associação entre eles ocorre a partir do primeiro dia da doença e destacou a importância da infecção pelo Cryptosporidium spp., agente encontrado em todos os momentos e animais.

Agradecimentos.- À Coordenação de Aperfeiçoamento de Pessoal de Nível Superior (CAPES), pela concessão de bolsa de mestrado e à Fundação de Amparo à Pesquisa do estado de Minas Gerais (FAPEMIG) pelo apoio financeiro.

\section{REFERÊNCIAS}

Andrade G.I., Morcatti F.C., Santos E.L.S., Ferreira M.G., Galinari C.F., Facury Filho E.J., Carvalho A.U., Lage A.P. \& Heinemann M.B. 2012. Identification of virulence factors by multiplex PCR in Escherichia coli isolated from calves in Minas Gerais, Brasil. Trop. Anim. Health Prod. 44:1783-1790.

Barrow P.A., Jones M.A. \& Thomson N. 2010. Salmonella, p.231-265. In: Gyles C.A., Prescott J.F., Songer J.G. \& Thoen C.O. (Eds), Pathogenesis of Bacterial Infections in Animals. $4^{\text {th }}$ ed. Wiley-Blackwell, Iowa.

Bartels C.J., Holzhauer M., Jorritsma R., Swart W.A.J.M. \& Lam T.J.G.M. 2010. 
Prevalence, prediction and risk factors of enteropathogens in normal and non-normal faeces of young Dutch dairy calves. Prev. Vet. Med. 93:162-169.

Batista C.G., Coelho S.G., Rabelo E., Lana A.M.Q., Carvalho A.U., Reis R.B. \& Saturnino H.M. 2008. Desempenho e saúde de bezerras alimentadas com leite sem resíduo de drogas antimicrobianas ou leite de vacas tratadas contra mastite adicionado ou não de probióticos. Arq. Bras. Med. Vet. Zootec. 60(1):185-191.

Becher K.A.I.D., Robertson D.M., Fraser D.G., Palmer D.G. \& Thompson R.C. 2004. Molecular epidemiology of Giardia and Cryptosporidium infections in dairy calves originating from three sources in Western Australia. Vet. Parasitol. 123:1-9.

Bowman D.D. 2006. Parasitologia Veterinária de Georgis. 8ª̣ ed. Manole, São Paulo. 422p.

Buzinaro M.G., Mistieri M.L.A., Carvalho A.A.B., Samara S.I., Regitano L.C.A. \& Jerez J.A. 2003. Prevalência de Rotavírus do grupo A em fezes diarreicas de bezerros de corte em sistema semi-intensivo de produção. Arq. Bras. Med. Vet. Zootec. 55(3):266-270.

Costa R.R., Santos E.E., Andrade M.A., Torres A.J.A., Ribeiro A.R. \& Carneiro J.B. 1979. Frequência e causas de doenças do aparelho digestivo em bezerros na bacia leiteira de Goiânia. Pesq. Agropec. Trop. 9:108-125.

Coura F.M. 2011. Estudo longitudinal prospectivo da incidência de enteropatógenos em bezerras em uma propriedade leiteira. Dissertação de Mestrado em Ciência Animal, Escola de Veterinária, Universidade Federal de Minas Gerais, Belo Horizonte, MG. 50p.

Davis C.L. \& Drackley J.K. 1998. The Development, Nutrition, and Management of the Young Calf. Iowa State University Press, Iowa. 354p.

Dodet B., Heseltine E., Mary C. \& Salion P. 1997. Rotaviruses in human and veterinary medicine. Sante 7:195-199.

Drackley J.K. 2008. Calf nutrition from birth to breeding. Vet. Clin. North. Am. Food Anim. Pract. 24:55-86.

Facury Filho E.J. 1992. Evolução da infecção por Eimeria spp. em bezerros naturalmente infectados e seu controle através da administração de anticoccídios no suplemento mineral. Dissertação de Mestrado em Ciência Animal, Escola de Veterinária, Universidade Federal de Minas Gerais, Belo Horizonte, MG. 136p.

Fayer R., Gasbarre L., Pasquali P., Canais A., Almeria S. \& Zarlenga D. 1998. Cryptosporidium parvum infection in bovine neonates: dynamic clinical, parasitic and immunologic patterns. Int. J. Parasitol. 28:49-56.

Ferreira M.G., Facury Filho E.J., Heinemann M.B., Carvalho A.U., Lage A.P., Ferreira P.M. \& Freitas M.D. 2009. Prevalência de Eimeria, helmintos, Escherichia coli, Salmonella, Rotavírus, Coronavírus e Cryptosporidium parvum em propriedades leiteiras de Minas Gerais. Ciênc. Anim. Bras. S.1:524-529.

Franck S.M., Bosworth B.T. \& Moon H.W. 1998. Multiplex PCR for Enterotoxigenic, Attaching and Effacing, and Shiga Toxin-Producing Escherichia coli Strains from Calves. J. Clin. Microbiol. 36:1795-1797.

Freitas M.D. 2009. Avaliação dos parâmetros clínicos e laboratoriais de bezerras com diarreia neonatal naturalmente adquiridas. Dissertação de Mestrado em Ciência Animal, Escola de Veterinária, Universidade Federal de Minas Gerais, Belo Horizonte, MG. 79p.

Freitas M.D. 2013. Avaliação de diferentes protocolos de fluidoterapia em bezerros neonatos com diarreia. Tese de Doutorado em Ciência Animal, Escola de Veterinária, Universidade Federal de Minas Gerais, Belo Horizonte, MG. 222p.

García A., Ruiz-Santa-Quiteria J.A., Orden J.A., Cid D., Sanz R., Gómez-Bautista M. \& de la Fuente R. 2000. Rotavírus and concurrent infections with other enteropathogens in neonatal diarrheic dairy calves in Spain. Comp Immunol. Microbiol. Infect. Dis. 23:175-183.

Garcia L.S. \& Bruckner D.A. 1997. Diagnostic Medical Parasitology. Elsevier, New York. 937p.

Godden S.M. 2008. Colostrum management for dairy calves. Vet. Clin. North. Am. Food Anim. Pract. 24:19-39.

Guimaraes L.B., Facury Filho E.J., Carvalho A.U., Ferreira P.M., Ribeiro M.F.B., Ferreira M.G. \& Freitas. M.D. 2009. Comportamento da excreção de oocistos de Cryptosporidium spp. e de cistos de Giárdia spp. em bezerros infectados naturalmente. Ciênc. Anim. Bras. S.1:660-665.
Hall G.A., Jones P.W. \& Morgan J.H. 2004. Calf Diarrhea, p.185-214. In: Andrews H.A., Blowey R.W., Boyd H. \& Eddy R.G. (Eds), Bovine Medicine: diseases and husbandry of cattle. $2^{\text {nd }}$ ed. Wiley-Blackwell, Oxford.

Herring A.J., Inglis N.F., Ojeh C.K., Snodgrass D.R. \& Menzies J.D. 1982. Rapid diagnosis of rotavirus infection by direct detection of viral nucleic -acid in silver stained polyacrylamide gels. J. Clin. Microbiol. 16:473477.

Langoni H., Linhares A.C., Avila F.A., Silva A.V. \& Elias A.O. 2004. Contribuição ao estudo da etiologia das diarreias em bezerros de aptidão leiteira no Estado de São Paulo, Brasil. Braz. J. Vet. Res. Anim. Sci. 41:313-319.

Levine N.D. 1973. Protozoan Parasites of Domestic Animals and of Man. $2^{\text {nd }}$ ed. Urbana: Burgess Publishing Company, Minnesota. 406p.

Lorenz I. 2006. Diarrhoea of the young calf: an update. Anais XXIV World Buiatrics Congress, Nice, France, p.1-9. (Trabalho Completo)

Mayameei A., Mohammadi G., Yavari S., Afshari E. \& Omidi A. 2010. Evaluation of relationship between Rotavirus and Coronavirus infections with calf diarrhea by capture ELISA. Comp. Clin. Pathol. 19:553-557.

McEwen S.A., Martin S.W., Clarke R.C., Tamblyn S.E. \& McDermott J.J. 1988. The prevalence, incidence, geographical distribution, antimicrobial sensitivity patterns and plasmid profiles of milk filter Salmonella isolates from Ontario dairy farms. Can. J. Vet. Res. 52:18-22.

McGuirk S.M. 2008. Disease management of dairy calves and heifers. Vet. Clin. North Am., Food Anim. Pract. 24:139-153.

Mendonça C.L., Lazaro N.S., Castro R.S., Afonso J.A.B. \& Hofer E. 1996. Occurrence of enterotoxigenic Escherichia coli and Salmonella sp. in calves in the southern Agreste region of the state of Pernambuco, Brazil. Pesq. Vet. Bras. 16:127-131.

Nonnecke B.J., Foote M.R., Smith J.M., Pesch B.A. \& Van Amburgh M.E. 2003. Composition and functional capacity of blood mononuclear leukocyte populations from neonatal calves on standard and intensified milk replacer diets.J. DairySci. 86:3592-3604.

Ogassawara S., Castro J.M., Kasai N. \& Pena H.F.J. 1989. Cryptosporidium tipo C. muris em bovinos do estado de São Paulo. Anais 6o Seminário Brasileiro de Parasitologia Veterinária, Bagé, RS, p.123. (Resumo)

Oliveira Filho J.P., Silva D.P.G., Pacheco M.D., Mascarini L.M., Ribeiro M.G., Alfieri A.A., Alfieri A.F., Stipp D.T., Barros B.J.P. \& Borges A.S. 2007. Diarreia em bezerros da raça Nelore criados extensivamente: estudo clínico e etiológico. Pesq. Vet. Bras. 27:419-424.

Ortolani E.L. \& Soares P.C. 2003. Aspectos epidemiológicos de lacriptosporidiosis em becerros de rebaños lecheros. Parasitol. Latinoam. 58:122127.

Pelkonen S., Romppanen E.L., Siitonen A. \& Pelkonen J. 1994. Differentiation of Salmonella serovar Infantis isolates from human and animal sources by fingerprinting IS200 and 16S rrn loci. J. Clin. Microbiol. 32:2128-2133.

Popoff M.Y. \& Minor L.L. 2001. Antigenic formulas of the Salmonella serovars. $8^{\text {th }}$ ed. WHO Collaborating Center for Reference and Research on Salmonella, Institut Pasteur, Paris. 166p.

Quilez J., Sánchez-Acedo C., Del Cacho E., Clavel A. \& Causapé A.C. 1996. Prevalence of Cryptosporidium and Giardia infections in cattle in Aragón (northeastern Spain). Vet. Parasitol. 66:139-146.

Radostits O.M., Gay C.C., Hinchcliff K.W. \& Constable P.D. 2007. Veterinary Medice: a textbook of the diseases of cattle, horses, sheep, pigs and goats. $10^{\text {th }}$ ed. Elsevier, Philadelphia.2156p.

Reynolds D., Hall G., Debney T. \& Parsons K. 1985. Pathology of natural rotavirus infection in clinically normal calves. Res. Vet. Sci. 38:264-269.

SAEG. 2000. Sistema de Análises Estatísticas e Genéticas. UFV, Viçosa.

Silper B.F., Lana A.M.Q., Carvalho A.U., Ferreira C.S., Franzoni A.P.S., Lima J.A.M., Saturnino H.M., Reis R.B. \& Coelho S.G. 2014. Effects of milk replacer feeding strategies on performance, ruminal development, and metabolism of dairy calves. J. Dairy Sci. 97:1016-1025.

Silva T.M.A., Oliveira R.G., Mol J.P.S., Xavier M.N., Paixao T.A., Cortez A., Heinemann M.B., Richtzenhain L.J., Lage A.P. \& Santos R.L. 2009. Diagnóstico etiológico de aborto infeccioso bovino por PCR. Ciência Rural 39:2563-2570. 
Trotz-Williams L.A., Martin S.W., Leslie K.E., Duffield T., Nydam D.V. \& Peregrine A.S. 2007. Calf-level risk factors for neonatal diarrhea and shedding of Cryptosporidium parvum in Ontario dairy calves. Prev. Vet. Med. 82:12-28.

Tzipori S., Campbell I., Sherwood D., Snodgrass D.R. \& Whitelaw A. 1980. An outbreak of calf diarrhea attributed to cryptosporidial infection. Vet. Rec. 107:579-580.

Ueno H. \& Gonçalves P.C. 1998. Manual para Diagnóstico das Helmintoses de Ruminantes. Japan International Cooperation Agency, Tokyo, p.1428.
Urquhart G.M., Armour J., Duncan J.L. \& Ennings F.W. 1998. Parasitologia Veterinária. 2aㅡ ed. Guanabara Koogan, Rio de Janeiro. 285p.

Waltman W.D. 2000. Methods for the cultural isolation of Salmonella, p.355-372. In: Wray C. \& Wray A. (Eds), Salmonella in Domestic Animals. CABI Publishing, London.

Woodward B. 1998. Protein, calories, and immune defenses. Nutr. Rev. 56:84-92.

Wray C. \& Davies R.H. 2000. Salmonella infections in cattle, p.169-190. In: Wray C. \& Wray A. (Eds), Salmonella in Domestic Animals. CABI Publishing, London. 